RESPIRATORY INFECTION

\title{
Impact of severe acute respiratory syndrome (SARS) on pulmonary function, functional capacity and quality of life in a cohort of survivors
}

\author{
D S Hui, G M Joynt, K T Wong, C D Gomersall, T S Li, G Antonio, F W Ko, M C Chan, D P Chan, \\ M W Tong, T H Rainer, A T Ahuja, C S Cockram, J J Y Sung
}

Thorax 2005;60:401-409. doi: 10.1136/thx.2004.030205

See end of article for authors' affiliations

Correspondence to:

Dr D S Hui, Department of Medicine and

Therapeutics, Chinese University of Hong Kong

Prince of Wales Hospital

30-32 Ngan Shing St,

Shatin, NT, Hong Kong;

dschui@cuhk.edu.hk

Received 15 June 2004

Accepted 19 October 2004
Objective: To examine the impact of severe acute respiratory syndrome (SARS) on pulmonary function, exercise capacity, and health-related quality of life (HRQoL) among survivors.

Methods: 110 survivors with confirmed SARS were evaluated at the Prince of Wales Hospital, HK at the end of 3 and 6 months after symptom onset. The assessment included lung volumes (TLC, VC, RV, FRC), spirometry (FVC, FEV 1 ), carbon monoxide transfer factor (TLCO adjusted for haemoglobin), inspiratory and expiratory respiratory muscle strength (Pimax and Pemax), 6 minute walk distance (6MWD), chest radiographs, and HRQoL by SF-36 questionnaire.

Results: There were 44 men and 66 women with a mean (SD) age of 35.6 (9.8) years and body mass index of $23.1(4.8) \mathrm{kg} / \mathrm{m}^{2}$. Seventy (64\%) were healthcare workers. At 6 months 33 subjects $(30 \%)$ had abnormal chest radiographs; four (3.6\%), eight (7.4\%), and $17(15.5 \%)$ patients had FVC, TLC, and TLCO below $80 \%$ of predicted values; and $15(13.9 \%)$ and $24(22.2 \%)$ had Pimax and Pemax values below $80 \mathrm{~cm} \mathrm{H} \mathrm{H}_{2} \mathrm{O}$, respectively. The 6MWD increased from a mean (SD) of 464 (83) $\mathrm{m}$ at 3 months to 502 (95) $\mathrm{m}(95 \% \mathrm{Cl} 22$ to $54 \mathrm{~m}, \mathrm{p}<0.001)$, but the results were lower than normal controls in the same age groups. There was impairment of HRQoL at 6 months. Patients who required ICU admission $(n=31)$ had significantly lower FVC, TLC, and TLCO than those who did not.

Conclusion: The exercise capacity and health status of SARS survivors was considerably lower than that of a normal population at 6 months. Significant impairment in surface area for gas exchange was noted in $15.5 \%$ of survivors. The functional disability appears out of proportion to the degree of lung function impairment and may be related to additional factors such as muscle deconditioning and steroid myopathy.
S evere acute respiratory syndrome (SARS) is a recently emerged infectious disease caused by a SARS coronavirus (CoV). ${ }^{1-3}$ From 1 November 2002 to 31 July 2003, 8098 probable cases were reported worldwide with a death toll of $774 .{ }^{4}$ The clinical course of SARS is characterised by fever, myalgia, and other systemic symptoms that generally improve after a few days, followed by a second phase with recurrence of fever, oxygen desaturation, and radiological progression of pneumonia. ${ }^{5}$ The majority of patients improve with treatment, but $20-36 \%$ require intensive care unit (ICU) admission and $13-26 \%$ progress into acute respiratory distress syndrome (ARDS) necessitating invasive ventilatory support. $^{5-8}$ The lung pathology of fatal SARS cases was dominated by diffuse alveolar damage, epithelial cell proliferation, an increase in macrophages in the lung, and extensive consolidation, ${ }^{9-11}$ but features of bronchiolitis obliterans organising pneumonia were also noted. ${ }^{12}$ Previous studies on survivors of acute lung injury (ALI) ${ }^{13}$ and ARDS $^{14-17}$ unrelated to SARS have shown variable degrees of residual abnormalities in pulmonary function, exercise capacity, and impairment in health-related quality of life (HRQoL).

During the global outbreak of SARS in 2003, healthcare workers were particularly vulnerable as the viral load increased to peak levels around day 10 from symptom onset. $^{5-818}{ }^{19}$ In a major outbreak of SARS at our hospital, over half of those infected were previously healthy healthcare workers. ${ }^{6}$ High resolution computed tomography (HRCT) performed at 5 weeks after discharge selectively on 24 outpatients with residual opacities revealed multiple patchy ground glass appearance and interstitial thickening $(\mathrm{n}=9$, $38 \%$ ) whereas CT evidence of fibrotic changes was noted in 15 patients $(62 \%) .^{20}$ It is possible that ongoing active alveolitis-probably as a result of an uncontrolled host immune response triggered by the viral antigen-may lead to pulmonary fibrosis in some patients. It is thus important to follow these patients to detect and manage pulmonary sequelae and functional impairment.

We report the short to medium term outcome of a prospective follow up study of our cohort which was epidemiologically linked to a single index case during a major hospital outbreak in 2003. ${ }^{621}$ Serial lung function, exercise capacity, chest radiographs, and HRQoL were examined at 3 and 6 months after illness onset. In addition, SARS survivors who had required ICU admissions were compared with those who were treated on the medical wards with reference to the same outcome parameters.

\section{METHODS}

Subjects

This is a prospective longitudinal follow up study of patients with SARS who were discharged from our hospital after

\footnotetext{
Abbreviations: $\mathrm{BMI}$, body mass index; $\mathrm{CRP}, \mathrm{C}$-reactive protein; $\mathrm{FEV}_{1}$, forced expiratory volume in 1 second; FRC, functional residual capacity; FVC, forced vital capacity; HRQoL, health-related quality of life; LDH, lactate dehydrogenase; LOS, length of stay; 6MWD, 6 minute walk distance; 6MWT, 6 minute walk test; Pimax, Pemax, maximum static inspiratory and expiratory pressures; RV, residual volume; SARS, severe acute respiratory syndrome; TLC, total lung capacity; TLCO, carbon monoxide transfer factor
} 
surviving the major outbreak in 2003. The patients came from our previously reported cohort ${ }^{6}$ recruited over a period of 2 weeks from 11 March to 25 March 2003. The diagnosis of SARS was based on the CDC criteria at the time, ${ }^{22}$ and all patients had subsequent laboratory confirmation of SARS. ${ }^{23}$ The treatment and outcome of these patients during hospitalisation has been reported in detail elsewhere. ${ }^{23}$ This prospective outcome study of SARS survivors was approved by the ethics committee of the Chinese University of Hong Kong.

\section{Assessment}

Following discharge from hospital, patients were evaluated in the lung function laboratory at the end of 3 and 6 months after disease onset. During the visit, subjects were interviewed and underwent a physical examination, pulmonary function testing, respiratory muscle strength measurement, postero-anterior chest radiography, resting oximetry, and a standardised 6 minute walk test $(6 \mathrm{MWT}){ }^{24}{ }^{25}$ In addition, they completed the Medical Outcomes Study 36-item ShortForm General Health Survey (SF-36) to measure HRQoL. ${ }^{26}$

\section{6 minute walk test (6MWT)}

This provides a standardised, objective, integrated assessment of cardiopulmonary and musculoskeletal function that is relevant to daily activities. ${ }^{24} 25$ The self-paced 6MWT assesses the sub-maximal level of functional capacity ${ }^{25}$ and has been applied in a long term follow up study of survivors of ARDS. ${ }^{14}$ The 6 minute walk distances (6MWD) were compared with the normative reference data collected from a population survey of 538 normal healthy subjects in 2004 by the Coordinating Committee in Physiotherapy, HK Hospital Authority, on two separate days. The mean (SD) 6MWD of the controls $(n=538)$ on days 1 and 2 of assessment were 598.4 (98.7) $\mathrm{m}$ and 609.2 (100.4) $\mathrm{m}$, respectively, with an intra-class correlation coefficient of 0.87 (95\% CI 0.84 to 0.89 ), standard error of measurement $35.3 \mathrm{~m}$, minimum detectable change $97.8 \mathrm{~m}$, and limits of agreement 10.8 (95\% CI -87.1 to 108.6$) \mathrm{m}$. The $6 \mathrm{MWD}$ data stratified into different age groups are available for comparison with the SARS patients, although we have no access to individual data of this population survey.

\section{SF-36}

This includes eight multiple item domains that assess physical functioning (PF), social functioning (SF), role limitation due to physical problems (RP), role limitation due to emotional problems ( $\mathrm{RE})$, mental health $(\mathrm{MH})$, bodily pain (BP), vitality (VT), and general health (GH). ${ }^{26}$ Scores for each aspect can range from 0 (worst) to 100 (best) with higher scores indicating better HRQoL. The validated Chinese (HK) version of the SF- $36^{27}$ was used for this study and the results were compared with the HK normative data collected from a random telephone survey of 2410 Chinese adults aged 18 years or above. ${ }^{28}$ Based on this survey, SF-36 domain scores stratified into two age groups (18-40 years and 4164 years) are available ${ }^{28}$ for comparison with those of our SARS survivors.

\section{Lung function testing}

Lung volumes (total lung capacity (TLC), vital capacity (VC), residual volume $(\mathrm{RV})$, functional residual capacity (FRC) using the nitrogen washout method), spirometric parameters (pre and post bronchodilator forced vital capacity (FVC), forced expiratory volume in 1 second $\left(\mathrm{FEV}_{1}\right), \mathrm{FEV}_{\mathrm{l}} / \mathrm{FVC}$ ratio), and surface area for gas exchange (carbon monoxide transfer factor adjusted for haemoglobin (TLCO) and carbon monoxide transfer coefficient (KCO)) were measured using the SensorMedic Vmax System, USA. TLCO was determined by the single breath carbon monoxide technique using an infrared analyser. Spirometric tests $\left(\mathrm{FEV}_{1}\right.$ and FVC pre and post bronchodilator) were performed according to the standards of the American Thoracic Society. ${ }^{29}$ After the prebronchodilator measurement, salbutamol $400 \mu \mathrm{g}$ was given via a metered dose inhaler with a spacer. Spirometric testing was repeated 10 minutes later. An increase in $\mathrm{FEV}_{1}$ of more than $12 \%$ and more than $0.2 \mathrm{l}$ was regarded as a positive bronchodilator response. ${ }^{30}$ The results were compared with the normative data ${ }^{31}$ which have been widely adopted as the reference data in HK.

Measurement of the maximum static inspiratory pressure that a subject can generate at the mouth (Pimax) or the maximum static expiratory pressure (Pemax) is a simple way to gauge inspiratory and expiratory muscle strength. ${ }^{32}{ }^{33}$ Since respiratory muscle weakness may lead to a restrictive pattern on lung function testing, Pimax and Pemax were assessed with a mouth pressure meter via a flanged mouthpiece ${ }^{34}$ after full lung function testing. In a study of 24 normal subjects (23 Chinese and one Indian of mean age 29.2 years) in Singapore, the mean (SD) maximal static inspiratory effort from residual volume (Pdi Pimax) for the group was 83.5 (35.5) $\mathrm{cm} \mathrm{H}_{2} \mathrm{O}^{35}$ A Pimax of $-80 \mathrm{~cm} \mathrm{H}_{2} \mathrm{O}$ or a Pemax of $+80 \mathrm{~cm} \mathrm{H}_{2} \mathrm{O}$ generally excludes clinically significant weakness of the inspiratory or expiratory muscles. ${ }^{36}$

To protect lung function laboratory staff, extra exhaust fans were installed in the lung function room and staff wore personal protective equipment including N95 respirators, protective goggles, gloves, and gowns. In addition, a disposable viral and bacterial filter (Spiroguard 2800/01, USA) was used for each patient during each visit.

\section{Radiographic assessment}

Frontal chest radiographs were performed at 3 and 6 months using standardised techniques with computed radiography equipment as reported during the major hospital outbreak. ${ }^{6}$ The images were assessed using a PACs system (Siemens Magicview Version VA22E, Germany) viewer (Siemens 2K monitor). Each lung was divided into three zones (upper, middle and lower) on the frontal radiograph. The observers assessed the presence, appearances (airspace opacities or reticular opacities), distribution, and size of lung parenchymal abnormalities on each chest radiograph of all patients. The size of the lesion was assessed by visually estimating the percentage area occupied in each zone on each side. The overall percentage of involvement was obtained by averaging the percentage involvement of the six lung zones. The frontal chest radiograph closest to the date of the lung function test was assessed by two radiologists, both blinded to the clinical information. Agreement was reached by consensus. The assessment method was as described in our previous study. ${ }^{37}$

\section{Analysis of data}

Statistical analysis was performed using Statistical Package for Social Science (SPSS) Version 11.0. Cumulative steroid dosage during inpatient treatment and outpatient follow up was converted into hydrocortisone $(\mathrm{mg})$ to facilitate analysis of the study. Continuous variables were compared using an independent sample $t$ test and the Mann-Whitney U test was used for non-parametric data. Categorical variables were compared using the $\chi^{2}$ test. All statistical tests were two tailed. Statistical significance was taken as $\mathrm{p}<0.05$. Univariate analyses were performed to evaluate the potential determinants of exercise capacity expressed as the 6MWD. Variables significant in the univariate analyses $(p<0.1)$ were included in the multivariate analysis. Age and sex were included in the final multivariable models because they are independent determinants of the $6 \mathrm{MWD} .^{38}$ 
Table 1 Results of serial pulmonary function tests and respiratory muscle strength among SARS survivors $(n=110)$

\begin{tabular}{lll}
\hline Parameter & 3 months & 6 months \\
\hline FVC (\% of predicted) & $104.5(95.0-114.0)$ & $104.5(95.0-113.0)$ \\
FEV $1 \%$ of predicted) & $108.0(99.0-118.5)$ & $106.0(97.8-116.0)$ \\
TLC (\% of predicted) & $104.0(93.3-115.8)$ & $108.0(98.0-117.0)$ \\
VC (\% of predicted) & $105.0(95.0-115.5)$ & $105.5(95.0-113.5)$ \\
RV (\% of predicted) & $108.0(70.5-140.8)$ & $115.0(84.0-139.8)$ \\
TLCO (\% of predicted) & $98.0(88.5-107.0)$ & $95.5(85.0-106.0)$ \\
KCO (\% of predicted) & $106.0(98.0-115.5)$ & $110.5(100.0-119.0)^{*}$ \\
Pimax (\% of predicted) & $104.0(88.0-127.0)$ & $101.0(87.5-125.0)$ \\
Pemax (\% of predicted) $74.0(62.0-86.0)$ & $77.0(59.0-86.0)$ \\
\hline
\end{tabular}

TLC, total lung capacity; VC, vital capacity; FVC, forced vital capacity; $\mathrm{FEV}_{1}$, forced expiratory volume in 1 second; RV, residual volume; TLCO, carbon monoxide transfer factor adjusted for haemoglobin; KCO, transfer coefficient (transfer factor per alveolar volume); Pimax, Pemax, maximum static inspiratory and expiratory pressures.

Values are expressed as median (interquartile range)

${ }^{*} \mathrm{p}<0.01, \mathrm{KcO}$ at 3 months $v 6$ months. No statistically significan

differences were noted between other lung function parameters at 3 and 6 months.

\section{RESULTS}

Of the first 138 patients infected with SARS in March 2003, 15 (10.9\%) died. ${ }^{23}$ Among the 123 survivors, 13 (10.6\%) did not attend for follow up (three returned overseas and 10 refused to participate in the study). A total of 110 were therefore available for analysis, 70 (64\%) of whom were healthcare workers (doctors, nurses, ward assistants, and medical students). Sixty six (60\%) patients were women. The mean (SD) age was $35.6(9.8)$ years and the body mass index (BMI) was $23.1(4.8) \mathrm{kg} / \mathrm{m}^{2}$ during the visit at 3 months from illness onset. The mean (SD) length of stay (LOS) in hospital for the group was 22.0 (13.9) days. There were only three smokers $(2.7 \%)$ among the whole group.

Seventeen patients had medical co-morbidities which included chronic obstructive pulmonary disease (COPD; $\mathrm{n}=\mathrm{l}(0.9 \%))$, ischaemic heart disease (IHD; $\mathrm{n}=\mathrm{l}(0.9 \%))$, ischaemic stroke $(\mathrm{n}=1(0.9 \%))$, breast cancer stable on tamoxifen $(\mathrm{n}=1(0.9 \%))$, diabetes mellitus $(\mathrm{n}=3(2.7 \%))$, cirrhosis $(n=1(0.9 \%))$, hypertension $(n=4(3.6 \%))$, and five asymptomatic hepatitis B carriers $(4.5 \%)$.

Among the 110 patients, 31 (28.2\%; 17 men and 14 women) had required admission to the ICU with a mean (SD) LOS of 13.5 (15.6) days (median 7, range 2-64); six $(5.5 \%)$ required invasive mechanical ventilation. Based on our ICU admission criteria, ${ }^{23}$ all the 31 patients would have a $\mathrm{PaO}_{2} / \mathrm{FiO}_{2}$ ratio $<300 \mathrm{~mm} \mathrm{Hg}$ while the six patients who were intubated had $\mathrm{a}_{\mathrm{PaO}_{2}} / \mathrm{FiO}_{2}$ ratio $<200 \mathrm{~mm} \mathrm{Hg}$. Among these 31 patients, six had medical co-morbidities (one IHD, one diabetes mellitus, two hypertension, and two asymptomatic hepatitis B carriers), but none had any history of smoking or pulmonary disease.

\section{Lung function tests and respiratory muscle strength}

An overview of the serial lung function test and respiratory muscle strength results for the group is shown in table 1. At 3 months 89 patients $(80.9 \%)$ had an $\mathrm{FEV}_{1} / \mathrm{FVC}$ ratio of $>80 \%$ while one patient with COPD (0.9\%) had an $\mathrm{FEV}_{1} / \mathrm{FVC}$ ratio of $<70 \%$. Overall, the lung volume parameters and surface area for exchange were well preserved at 3 and 6 months. A significant proportion of patients appeared to have increased RV at 3 and 6 months (median (interquartile range, IQR) $108(71-141) \%$ and 115 (84-140)\%, respectively. Although none complained of symptoms of asthma, seven $(6.4 \%)$ had a significant bronchodilator response with increments of $\mathrm{FEV}_{1}>200 \mathrm{ml}$ after inhalation of salbutamol at 3 months. $22(20.6 \%)$ and eight (7.5\%) patients, respectively, had Pimax and Pemax values below $80 \mathrm{~cm} \mathrm{H}_{2} \mathrm{O}$.

At 6 months $79(71.8 \%)$ had an $\mathrm{FEV}_{1} / \mathrm{FVC}$ ratio of $>80 \%$ while the same patient with COPD had an $\mathrm{FEV}_{\mathrm{l}} / \mathrm{FVC}$ ratio of $<70 \%$. None had a significant bronchodilator response after inhalation of salbutamol. 15 (13.9\%) and 24 (22.2\%) subjects, respectively, had Pimax and Pemax values below $80 \mathrm{~cm} \mathrm{H}_{2} \mathrm{O}$. There was a slight increase in Kco but no change in other lung function parameters at 6 months compared with 3 months (table 1).

The frequency of lung function parameters below $80 \%$ of predicted values in SARS survivors is shown in table 2. Seventeen patients $(15.5 \%)$ had impaired TLCo while up to $7.3 \%$ of patients had reduced lung volume measurements at 6 months.

\section{MWD}

The $6 \mathrm{MWD}$ of the SARS survivors at 3 and 6 months, compared with normative data, is shown in table 3 . The mean 6MWD increased significantly from $464 \mathrm{~m}$ at 3 months to $502 \mathrm{~m}$ at 6 months ( $95 \%$ CI of difference 22 to $54, \mathrm{p}<0.01$ ). When the subjects were stratified into different age groups and compared with the corresponding normative values, their exercise capacity was significantly lower than the normal subjects (table 3 ). There was no difference in oxygen saturation after exercise at 3 and 6 months (97.8 (2.6)\% $v$ $97.4(8.8) \%, p=0.61)$. Two patients and one patient, respectively, had $\mathrm{SaO}_{2}<88 \%$ after $6 \mathrm{MWT}$ at 3 and 6 months.

Univariate analysis was performed to look for factors associated with 6MWD. At 3 months, age ( $\beta$ coefficient -2.48 (SE 0.79), $p=0.002$ ), female sex ( $\beta$ coefficient -43.33 (15.82), $p=0.007)$, and hospital LOS ( $\beta$ coefficient -1.72 $(0.55), p=0.002)$ were significant negative predictors of $6 \mathrm{MWD}$ whereas total dose of steroid ( $\beta$ coefficient 0.00 $(0.00), p=0.86)$, ICU admission ( $\beta$ coefficient -8.27 (17.81), $\mathrm{p}=0.64)$, baseline lactate dehydrogenase $(\mathrm{LDH}) \quad(\beta$ coefficient $-0.02(0.05), p=0.69)$, peak LDH ( $\beta$ coefficient -0.01 $(-0.02), \quad p=0.848)$, BMI $(\beta$ coefficient $-2.16 \quad(1.66)$, $\mathrm{p}=0.20)$, and peak CRP ( $\beta$ coefficient 0.25 (0.17), $\mathrm{p}=0.143$ ) were not. Following multivariate analysis (adjusted $R^{2}=0.17$ ), the independent negative predictors

Table 2 Frequency of lung function parameters below normal range in SARS patients

\begin{tabular}{|c|c|c|c|c|c|c|}
\hline & \multicolumn{2}{|c|}{$\mathrm{N}<60 \%$ predicted value } & \multicolumn{2}{|c|}{$\mathrm{N}<70 \%$ predicted value } & \multicolumn{2}{|c|}{$\mathrm{N}<80 \%$ predicted value } \\
\hline & 3 months & 6 months & 3 months & 6 months & 3 months & 6 months \\
\hline $\mathrm{FEV}_{1}$ & 0 & 0 & $2(1.8 \%)$ & $1(0.9 \%)$ & $3(2.7 \%)$ & $4(3.6 \%)$ \\
\hline FVC & $1(0.9 \%)$ & 1 (0.9\%) & $1(0.9 \%)$ & $1(0.9 \%)$ & $6(5.5 \%)$ & $4(3.6 \%)$ \\
\hline VC & $1(0.9 \%)$ & $2(1.8 \%)$ & $2(1.8 \%)$ & $3(2.7 \%)$ & $6(5.5 \%)$ & $5(4.5 \%)$ \\
\hline TLC & 0 & 0 & $3(2.7 \%)$ & $2(1.8 \%)$ & $7(6.4 \%)$ & $8(7.3 \%)$ \\
\hline TLCO & $2(1.8 \%)$ & $7(6.4 \%)$ & $7(6.4 \%)$ & $9(8.2 \%)$ & $14(12.7 \%)$ & $17(15.5 \%)$ \\
\hline $\mathrm{KCO}$ & 0 & 0 & 0 & 0 & $2(1.8 \%)$ & $1(0.9 \%)$ \\
\hline
\end{tabular}

TLC, total lung capacity; VC, vital capacity; FVC, forced vital capacity; FEV 1 , forced expiratory volume in 1 second; TLCO, carbon monoxide transfer factor adjusted for haemoglobin; KCO, transfer coefficient (transfer factor per alveolar volume). 
Table 3 Six minute walking distance (6MWD) among SARS survivors $(n=110)$ at 3 and 6 months after the onset of illness compared with Hong Kong normative data

\begin{tabular}{|c|c|c|c|c|c|}
\hline Outcome & & Normal & 3 months & 6 months & p valuet \\
\hline All survivors $\left(n=110^{*}\right)$ & Mean (SD) & & $464(83)$ & $502(95)$ & ** \\
\hline \multicolumn{6}{|l|}{ Age group (years) } \\
\hline $21-30(n=37)$ & & & & & 0.01 \\
\hline Men & $\begin{array}{l}\text { Mean (SD) } \\
\text { Mean difference }(95 \% \mathrm{Cl})\end{array}$ & $651(105),(n=80)$ & $\begin{array}{l}487(58),(n=17) \\
-164(-201 \text { to }-127)^{* *}\end{array}$ & $\begin{array}{l}549(73),(n=17) \\
-102(-155 \text { to }-49)^{* *}\end{array}$ & \\
\hline Women & $\begin{array}{l}\text { Mean (SD) } \\
\text { Mean difference }(95 \% \mathrm{Cl})\end{array}$ & $600(84),(n=85)$ & $\begin{array}{l}461(75),(n=20) \\
-139(-180 \text { to }-98)^{\star *}\end{array}$ & $\begin{array}{l}493(92),(n=20) \\
-107(-149 \text { to }-65)^{\star *}\end{array}$ & 0.13 \\
\hline \multicolumn{6}{|l|}{$31-40(n=40)$} \\
\hline Men & $\begin{array}{l}\text { Mean (SD) } \\
\text { Mean difference }(95 \% \mathrm{Cl})\end{array}$ & $645(93),(n=78)$ & $\begin{array}{l}513(80),(n=19) \\
-132(-178 \text { to }-86)^{* *}\end{array}$ & $\begin{array}{l}551(98),(n=19) \\
-94(-141 \text { to } 46)^{\star *}\end{array}$ & 0.06 \\
\hline Women & $\begin{array}{l}\text { Mean (SD) } \\
\text { Mean difference }(95 \% \mathrm{CI})\end{array}$ & $606(86),(n=108)$ & $\begin{array}{l}476(71),(n=22) \\
-130(-169 \text { to } 91)^{* *}\end{array}$ & $\begin{array}{l}502(53),(n=22) \\
-101(-139 \text { to }-63)^{* *}\end{array}$ & 0.11 \\
\hline \multicolumn{6}{|l|}{$41-50(n=21)$} \\
\hline Men & $\begin{array}{l}\text { Mean (SD) } \\
\text { Mean difference }(95 \% \mathrm{Cl})\end{array}$ & $623(80),(n=38)$ & $\begin{array}{l}477(82),(n=7) \\
-146(-212 \text { to }-79)^{* *}\end{array}$ & $\begin{array}{l}543(112),(n=7) \\
-80(-151 \text { to }-9), p=0.03\end{array}$ & 0.09 \\
\hline Women & $\begin{array}{l}\text { Mean (SD) } \\
\text { Mean difference }(95 \% \mathrm{CI})\end{array}$ & $541(67),(n=79)$ & $\begin{array}{l}404(83),(n=14) \\
-137(-177 \text { to }-97)^{\star *}\end{array}$ & $\begin{array}{l}473(76),(n=14) \\
-68(-107 \text { to }-29)^{* *}\end{array}$ & ** \\
\hline \multicolumn{6}{|l|}{$51-60(n=11)$} \\
\hline Men & $\begin{array}{l}\text { Mean (SD) } \\
\text { Mean difference }(95 \% \mathrm{Cl})\end{array}$ & $588(68),(n=23)$ & $\begin{array}{l}331(83),(n=2) \\
-257(-361 \text { to }-152)^{* *}\end{array}$ & $\begin{array}{l}405(89),(n=2) \\
-183(-288 \text { to }-78)^{\star *}\end{array}$ & 0.18 \\
\hline Women & $\begin{array}{l}\text { Mean (SD) } \\
\text { Mean difference }(95 \% \mathrm{Cl})\end{array}$ & $534(89),(n=33)$ & $\begin{array}{l}399(92),(n=9) \\
-135(-203 \text { to }-67)^{* *}\end{array}$ & $\begin{array}{l}371(99),(n=9) \\
-163(-232 \text { to }-94)^{* *}\end{array}$ & 0.67 \\
\hline
\end{tabular}

for 6MWD were female sex ( $\beta$ coefficient -38.02 (15.18), $p=0.014)$ and hospital LOS ( $\beta$ coefficient $-1.28(0.57)$, $\mathrm{p}=0.028)$, with a trend for age being a negative predictor $(\beta$ coefficient $-1.54(0.82), \mathrm{p}=0.063)$. Based on this model, the mean (SE) difference in 6MWD between women and men after adjusting for hospital LOS was -34.0 (14.8) $\mathrm{m}(95 \% \mathrm{CI}$ -63.5 to -4.6$), \mathrm{p}=0.024$.

At 6 months, age ( $\beta$ coefficient -3.31 (SE 0.88), $p<0.001$ ), female sex $(\beta$ coefficient $-67.62(17.41), p<0.001)$, and hospital LOS ( $\beta$ coefficient -1.39 (0.65), $p=0.036$ ) were significant negative predictors of $6 \mathrm{MWD}$ whereas total dose of steroid ( $\beta$ coefficient $0.00(0.00), p=0.66)$, ICU admission ( $\beta$ coefficient 28.17 (20.37), $p=0.17)$, baseline LDH $(\beta$ coefficient $0.06(0.06), p=0.31)$, peak LDH ( $\beta$ coefficient 0.07 (0.13), $\mathrm{p}=0.19$ ), BMI ( $\beta$ coefficient -2.59 (2.04), $p=0.21)$, and peak CRP $(\beta$ coefficient $0.26(0.21), p=0.20)$ were not. Following multivariate analysis (adjusted $R^{2}=0.20$ ), the independent negative predictors for 6MWD were age $(\beta$ coefficient $-2.53(0.91), p=0.006)$ and female $\operatorname{sex}(\beta$ coefficient -60.11 (16.74), $\mathrm{p}<0.001$ ) whereas hospital LOS was no longer a factor $(\beta$ coefficient -0.71 (0.63), $\mathrm{p}=0.264$ ). Based on this model, the adjusted mean (SE) difference in 6MWD between women and men was -55.3 (16.3) $\mathrm{m},(95 \% \mathrm{CI}-87.6$ to -30.0$), \mathrm{p}=0.001$.

\section{Chest radiographs and correlations with lung function and $6 M W D$}

Thirty eight patients $(35.8 \%)$ had abnormal total chest radiographic scores at 3 months involving a mean (SD) of $3.9(3.5) \%$ (range $0.5-15)$ of the total lung fields. These included eight patients with abnormal scores in both airspace opacity and reticular shadows, 16 with an abnormal airspace score, and 14 with an abnormal reticular score. At 6 months 33 subjects $(30 \%)$ still had abnormal chest radiographic scores involving 3.1 (3.3)\% (range $0.8-15)$ of the lung fields. These included three patients with abnormalities in both

Table 4 Comparison of demographic characteristics, biochemical markers, and steroid dosage in SARS survivors who required ICU care versus those treated on medical wards

\begin{tabular}{|c|c|c|c|c|}
\hline & $\begin{array}{l}\text { ICU } \\
(n=31)\end{array}$ & $\begin{array}{l}\text { Non-ICU } \\
(n=79)\end{array}$ & $95 \% \mathrm{Cl}$ & p value \\
\hline Age (years) & $38.4(9.8)$ & $33.9(9.4)$ & -8.6 to -0.5 & $0.03^{*}$ \\
\hline Male sex & $17 / 31$ & $26 / 79$ & 1 & 0.05 \\
\hline BMI $\left(\mathrm{kg} / \mathrm{m}^{2}\right), 3$ months & $24.0(3.8)$ & $22.6(5.1)$ & -3.4 to 0.6 & 0.17 \\
\hline BMI $\left(\mathrm{kg} / \mathrm{m}^{2}\right), 6$ months & $24.3(3.8)$ & $23.0(4.7)$ & -3.1 to 0.7 & 0.20 \\
\hline Hospital LOS (days) & $32.4(19.8)$ & $17.9(7.7)$ & -29.8 to -7.3 & $<0.01^{*}$ \\
\hline CRP baseline (mg/dl) & $26.4(28.1)$ & $23.2(32.1)$ & -17.1 to 10.8 & 0.65 \\
\hline CRP peak (mg/dl) & $77.1(61.6)$ & $36.4(39.2)$ & -65.6 to -15.8 & $<0.01^{*}$ \\
\hline LDH baseline (U/I) & $357.8(201.3)$ & $274.6(155.9)$ & -167.6 to 1.4 & 0.05 \\
\hline LDH peak (U/I) & $522.3(157.0)$ & 349.4 (165.5) & -244.7 to -101.1 & $<0.01^{*}$ \\
\hline Cumulative steroid dosage (hydrocortisone, $\mathrm{mg}$ ) & $18881(11425)$ & $8217(5874)$ & -15044 to -6284 & $<0.01^{*}$ \\
\hline Radiographic total score (\%), 6 months & $1.9(3.7)$ & $0.6(1.3)$ & -2.7 to 0.1 & 0.06 \\
\hline
\end{tabular}

Values are expressed as mean (SD).

BMI, body mass index; CRP, C-reactive protein; LOS, length of stay; LDH, lactate dehydrogenase; $95 \% \mathrm{Cl}, 95 \%$ confidence interval of the difference between groups.

*Statistically significant. 
Table 5 Comparison of lung function indices, respiratory muscle strength, and 6MWD in SARS survivors who had required ICU care $(n=31)$ versus those treated on the wards $(n=79)$

\begin{tabular}{|c|c|c|c|}
\hline & 3 months & 6 months & Mean (SE) difference 6-3 months \\
\hline \multicolumn{4}{|l|}{ FVC (\% of predicted) } \\
\hline Mean (SD) & $94.3(14.0)$ v $107.6(12.1)$ & $98.6(15.8)$ v $106.1(13.5)$ & $4.3(1.7) v-1.6(1.0)$ \\
\hline $95 \% \mathrm{Cl}$ & 7.9 to 18.7 & 1.5 to 13.5 & -9.6 to -2.1 \\
\hline$p$ value & $p<0.01^{*}$ & $p=0.02^{*}$ & $\mathrm{p}<0.01^{*}$ \\
\hline \multicolumn{4}{|l|}{$\mathrm{FEV}_{1}$ (\% of predicted) } \\
\hline Mean (SD) & $102.0(13.1)$ v 111.1 (14.7) & $103.8(12.7)$ v $108.2(15.4)$ & $1.8(1.2) v-2.9(1.3)$ \\
\hline $95 \% \mathrm{Cl}$ & 3.0 to 15.1 & -1.8 to 10.6 & -9.0 to -0.4 \\
\hline \multirow{2}{*}{\multicolumn{4}{|c|}{ VC (\% of predicted) }} \\
\hline & & & \\
\hline Mean (SD) & $94.7(15.1)$ v $107.9(12.5)$ & $98.4(16.4)$ v $105.0(17.9)$ & $3.7(1.4) v-2.8(1.4)$ \\
\hline $95 \% \mathrm{Cl}$ & 7.4 to 18.9 & -0.9 to 14.1 & -11.3 to -1.8 \\
\hline $\mathrm{p}$ value & $p<0.01^{*}$ & $p=0.08$ & $p=0.01^{*}$ \\
\hline \multicolumn{4}{|l|}{ TLC (\% of predicted) } \\
\hline Mean (SD) & $94.6(16.1) \vee 110.3(16.4)$ & $98.2(19.3)$ v 110.1 (14.1) & $3.6(3.9) v-0.2(1.9)$ \\
\hline $95 \% \mathrm{Cl}$ & 8.7 to 22.7 & 4.0 to 19.7 & -11.6 to 4.0 \\
\hline$p$ value & $p<0.01^{*}$ & $p<0.01^{*}$ & $p=0.33$ \\
\hline \multicolumn{4}{|l|}{ RV (\% of predicted) } \\
\hline Mean (SD) & $96.7(39.4)$ v $115.7(49.7)$ & $99.9(51.6)$ v $118.6(38.5)$ & $3.2(12.3)$ v $2.9(6.2)$ \\
\hline $95 \% \mathrm{Cl}$ & -1.2 to 39.2 & -2.4 to 39.7 & -25.0 to 24.3 \\
\hline$p$ value & $p=0.06$ & $p=0.08$ & $p=0.98$ \\
\hline \multicolumn{4}{|l|}{ TLCO (\% of predicted) } \\
\hline Mean (SD) & $84.3(17.5)$ v $101.4(13.4)$ & $87.7(21.0) \vee 98.3(16.6)$ & $3.4(2.2) v-2.9(1.6)$ \\
\hline $95 \% \mathrm{Cl}$ & 10.9 to 23.4 & 3.0 to 18.2 & -11.9 to -0.6 \\
\hline \multirow{2}{*}{\multicolumn{4}{|c|}{ Kco (\% of predicted) }} \\
\hline & & & \\
\hline Mean (SD) & $104.9(13.5)$ v 107.4 (13.7) & $109.4(15.3)$ v $110.1(13.6)$ & \\
\hline $95 \% \mathrm{Cl}$ & -3.4 to 8.2 & -5.3 to 6.7 & -6.5 to 2.7 \\
\hline$p$ value & $p=0.41$ & $P=0.83$ & $p=0.42$ \\
\hline \multicolumn{4}{|l|}{ Pimax (\% of predicted) } \\
\hline Mean (SD) & $104.2(29.1)$ v $108.5(29.8)$ & $105.6(30.6)$ v $105.8(25.8)$ & $0.6(5.6) v-2.6(2.7)$ \\
\hline $95 \% \mathrm{Cl}$ & -8.5 to 17.0 & -11.4 to 11.8 & -14.0 to 7.6 \\
\hline $\mathrm{p}$ value & $p=0.51$ & $P=0.97$ & $p=0.56$ \\
\hline \multicolumn{4}{|l|}{ Pemax (\% of predicted) } \\
\hline Mean (SD) & $75.7(14.9) \vee 73.2(18.9)$ & $74.5(19.1)$ v $71.5(21.4)$ & $-1.8(2.8) v-1.5(2.1)$ \\
\hline $95 \% \mathrm{Cl}$ & -10.2 to 5.2 & -11.9 to 5.8 & -7.1 to 7.6 \\
\hline$p$ value & $p=0.52$ & $P=0.49$ & $p=0.94$ \\
\hline \multicolumn{4}{|l|}{$6 \mathrm{MWD}(\mathrm{m})$} \\
\hline Mean (SD) & $458.2(86.8)$ v $466.4(80.7)$ & $519.7(101.4) \vee 491.5(92.9)$ & $64.5(14.5) \vee 25.1(9.7)$ \\
\hline $95 \% \mathrm{Cl}$ & -27.1 to 43.6 & -11.4 to 11.8 & -74.9 to -4.0 \\
\hline$p$ value & $p=0.64$ & $P=0.97$ & $p=0.03^{*}$ \\
\hline \multicolumn{4}{|c|}{$\begin{array}{l}\text { FVC, forced vital capacity; } \mathrm{FEV}_{1} \text {, forced expiratory volume in } 1 \text { second; } \mathrm{VC} \text {, vital capacity; TLC, total lung capacity; RV, residual volume; TLCO, carbon monoxide } \\
\text { transfer factor adjusted for haemoglobin; KCO, transfer coefficient (transfer factor per alveolar volume); Pimax, Pemax, maximum static inspiratory and expiratory } \\
\text { pressures; } 6 \mathrm{MWD}, 6 \text { minute walk distance. } \\
\text { Values are shown as mean (SD) ICU } v \text { non-ICU with } 95 \% \mathrm{Cl} \text { of difference and p values. } \\
\text { *Statistically significant. }\end{array}$} \\
\hline
\end{tabular}

airspace and reticular shadows, 16 with abnormal airspace shadows, and 14 with abnormal reticular shadows.

Correlations between the extent of radiographic abnormality and cumulative steroid dosage, lung function parameters, and 6MWD at 6 months were examined. There was a significant positive correlation between the extent of radiographic abnormalities ( $\%$ of lung fields) and the cumulative hydrocortisone dosage $(r=0.38, \mathrm{p}<0.01)$, and a significant negative correlation between the extent (\%) of radiographic abnormalities and FVC $(r=-0.23, \mathrm{p}=0.02)$, TLC $(r=-0.22$, $\mathrm{p}=0.02)$, TLCO $(r=-0.29, \mathrm{p}<0.01)$, and KCO $(r=-0.22$, $\mathrm{p}=0.02$ ) with a trend towards a negative correlation with VC $(r=-0.17, \mathrm{p}=0.07)$. However, no significant correlations were noted between the extent of radiographic abnormalities and 6MWD $(r=-0.14, \mathrm{p}=0.15), \mathrm{FEV}_{1}(r=-0.12, \mathrm{p}=0.20)$, RV $(r=-0.11, \mathrm{p}=0.25)$, Pimax $(r=0.10, \mathrm{p}=0.29)$, and

Table 6 Correlations between pulmonary function and HRQoL at 6 months $(n=110)$

\begin{tabular}{llllll}
\hline SF-36 & FVC & FEV $_{\mathbf{1}}$ & VC & TLC & TLCO* \\
\hline PF & $0.31^{*}$ & $0.40^{*}$ & $0.42^{*}$ & 0.19 & $0.30^{*}$ \\
RP & $0.31^{*}$ & $0.39^{*}$ & $0.35^{*}$ & 0.18 & $0.34^{*}$ \\
BP & 0.16 & $0.29^{*}$ & $0.27^{*}$ & 0.03 & 0.17 \\
GH & $0.29^{*}$ & $0.32^{*}$ & $0.29^{*}$ & 0.11 & $0.32^{*}$ \\
VT & 0.16 & $0.23 \dagger$ & 0.12 & 0.01 & 0.13 \\
SF & $0.24 \ddagger$ & $0.39^{*}$ & $0.24 \ddagger$ & 0.13 & $0.27 \ddagger$ \\
RE & 0.15 & $0.22 \dagger$ & $0.22 \dagger$ & -0.01 & $0.22 \dagger$ \\
MH & 0.13 & $0.22 \dagger$ & 0.09 & 0.02 & $0.26 \ddagger$ \\
\hline
\end{tabular}

$\mathrm{PF}$, physical functioning; $\mathrm{SF}$, social functioning; RP, role limitation due to physical problems; $\mathrm{RE}$, role limitation due to emotional problems; $\mathrm{MH}$, mental health; BP, bodily pain; VT, vitality; $\mathrm{GH}$, general health. Values shown are Pearson's correlation coefficients $(r)$. ${ }^{*} \mathrm{p}<0.01 ; \mathrm{tp}<0.05 ; \mathrm{fp}=0.05$. 


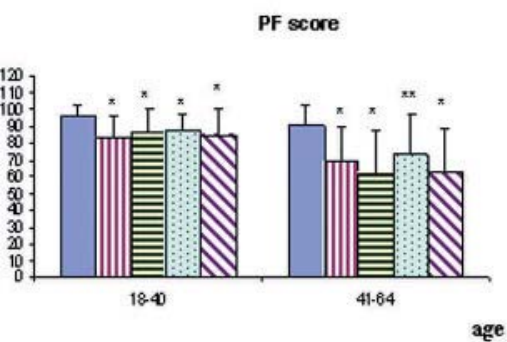

GH score

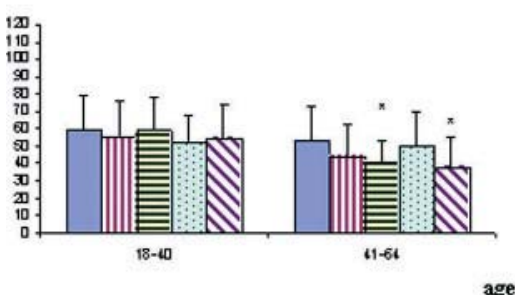

RE score

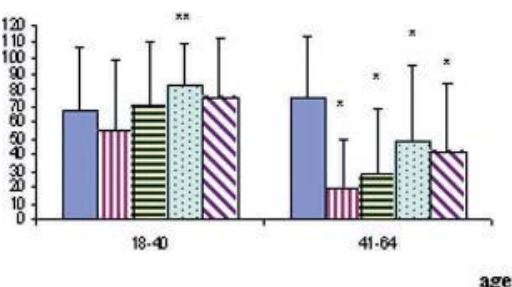

RP score

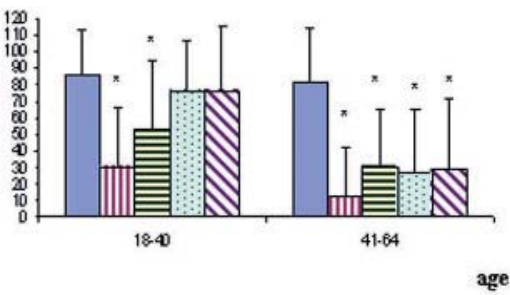

V score

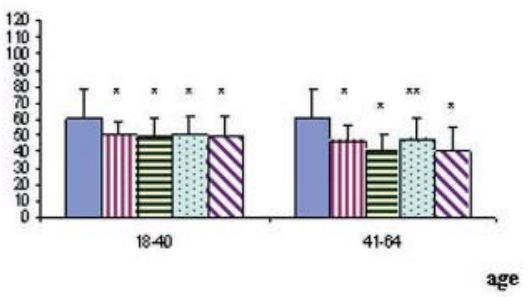

MH score

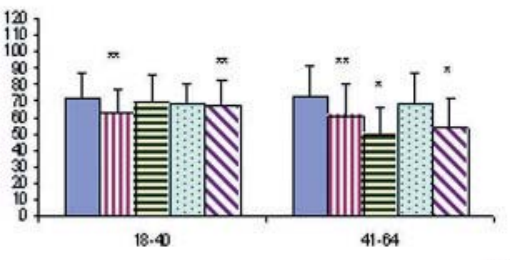

BP soore

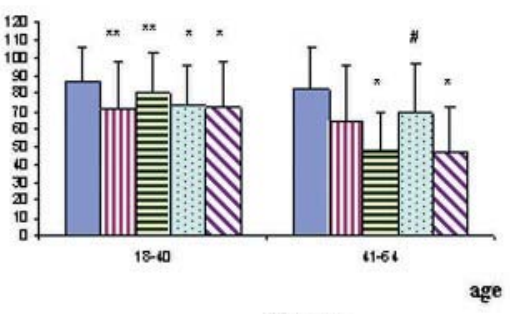

SF score

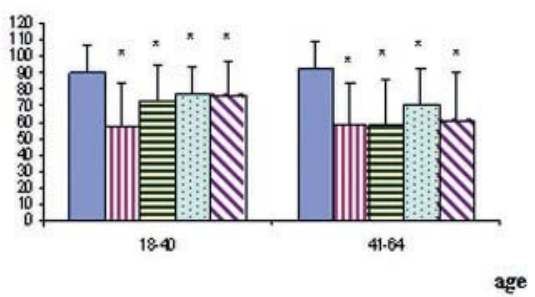

Figure 1 Health-related quality of life (SF-36) among SARS survivors at 3 and 6 months after illness onset compared with Hong Kong normative data stratified into different age groups. ${ }^{28}$ The vertical axis represents mean (SD) SF-36 domain scores from 0 (minimum) to 100 (maximum) and the horizontal axis defines age groups in years. Based on the study by Lam et a ${ }^{8}$ there were 1244 and 695 normal subjects in the age groups $18-$ 40 years and 41-64 years, respectively. There were 19 and 12 SARS survivors who had required ICU support in the age groups 18-40 years and 4164 years, and 60 and 19 SARS survivors, respectively, who did not require ICU support in the two age groups. PF, physical functioning; SF, social functioning; RP, role limitation due to physical problems; RE, role limitation due to emotional problems; $\mathrm{MH}$, mental health; $\mathrm{BP}$, bodily pain; VT, vitality; $\mathrm{GH}$, general health. ${ }^{*} \mathrm{p}<0.01 ;{ }^{* *} \mathrm{p}<0.03 ; \# \mathrm{p}<0.05$.

Pemax $(r=0.12, \mathrm{p}=0.21)$. These data are shown in a supplementary file available on the Thorax website at http:// www.thoraxjnl.com/supplemental.

\section{Comparison of patients requiring ICU support with those treated on the wards}

Patients who had required ICU admission $(\mathrm{n}=31,17$ men and 14 women) were older with a higher peak $\mathrm{LDH}$, a longer hospital LOS, and received a significantly higher total steroid dosage than those who did not require ICU care (table 4). The lung function tests at 6 months showed significantly lower FVC, TLC, and TLCO in survivors who had required ICU support than those who were treated on medical wards, although no significant differences were noted in 6MWD and respiratory muscle strength between the two groups (table 5).

\section{HRQoL among SARS survivors and its correlation with lung function parameters}

Correlations between lung function parameters and SF-36 domains at 6 months are shown in table 6 . In general there were significant positive correlations between lung function parameters (FVC, VC, $\mathrm{FEV}_{1}$, and TLCO) and several SF-36 domains (PF, RP, GH, and SF).

SF-36 domain scores at 3 and 6 months after illness onset of patients who did and did not require ICU support during the acute illness compared with normative data are shown in fig 1 (more data are available in supplemental tables $2 \mathrm{a}$ and $\mathrm{b}$ on the Thorax website http://www.thoraxjnl.com/ supplemental). There was significant impairment of HRQoL among the SARS survivors at 6 months.

When those who had required ICU admissions were directly compared with those treated on the medical wards there was a significantly lower score in RP $(p=0.026)$ and SF $(p=0.02)$ for those aged 18-40 years who had required ICU support $(n=19)$ but no significant difference in any domain for those aged 41-64 years $(n=12)$ at 3 months. There was no significant difference in SF-36 domains between the two groups at 6 months apart from a lower score in BP $(\mathrm{p}=0.021)$ for those aged 41-64 years who had required ICU support $(\mathrm{n}=12)$.

In comparing the 25 patients who did not require intubation in the ICU with those who had required intubation $(n=6)$, the latter had more severe lung injury as reflected by a higher peak LDH level (median 466.0 (IR 259.0) v 652.0 (124.5) $\mathrm{U} / \mathrm{l}, \mathrm{p}=0.02$ ). There was, however, no statistically significant difference with regard to age (36.0 (15.5) $v 36.5(17.5)$ years, $\mathrm{p}=0.87)$ and 6MWD (507.7 (163.9) $v 449.0(129.3) \mathrm{m}, \mathrm{p}=0.18$ ) at 6 months. In addition, there were no significant differences between the two groups with regard to lung function indices and SF-36 domain scores at 6 months (data available in supplemental table 3 on the Thorax website http://www.thoraxjnl.com/supplemental).

\section{DISCUSSION}

During the global outbreak of SARS in 2003 there was an enormous demand on ICU support for patients who developed severe respiratory failure. ${ }^{5-81819}$ Although the use of 
pulse methylprednisolone during clinical progression was associated with favourable clinical improvement in most of our patients with resolution of fever and improvement of lung opacities within 2 weeks, ${ }^{6} 233940$ our preliminary follow up study with HRCT scanning has revealed multiple patchy ground glass appearance and interstitial thickening in nine patients and CT evidence of fibrotic changes in 15 out of 24 patients with residual radiographic opacities. ${ }^{20}$ This has raised concern that some patients with SARS may have ongoing immune mediated alveolitis which has the potential to lead to significant parenchymal fibrosis and lung function impairment. A recent report by $\mathrm{Ng}$ et $a l^{41}$ has indicated that residual abnormalities of pulmonary function were still observed in three quarters of their cohort $(n=57)$, mostly consisting of isolated reductions in TLCO, while an abnormal HRCT score was detected in $75.4 \%$ of SARS patients at 6 months after admission to hospital.

This prospective cohort study has shown that most of the SARS survivors had relatively well preserved lung function at 6 months after symptom onset. Up to $15.5 \%$ of patients had significant impairment of lung function, as reflected by reduced TLCo with well preserved Kco. These results suggest an increase in the intra-alveolar diffusion pathway which may be the result of diffuse alveolar damage and/or bronchiolitis obliterans organising pneumonia in the acute stage, ${ }^{9-12}$ followed by post-inflammatory changes such as atelectasis, ongoing alveolitis, and parenchymal fibrosis later in the course of the disease. Several studies on ARDS survivors have shown that their pulmonary function generally returns to normal or near normal by $6-12$ months, ${ }^{42-44}$ but TLCO may remain abnormal in up to $80 \%$ of patients at 1 year after recovery. ${ }^{16}$

The self-paced 6MWT was performed to evaluate the global and integrated responses to exercise, and these would include cardiorespiratory systems, systemic and peripheral circulation, blood, neuromuscular units, and muscle metabolism. However, the 6MWT does not provide specific information on the function of individual organs and systems. ${ }^{25}$ The $6 \mathrm{MWD}$ was substantially reduced for all age groups at 3 and 6 months compared with controls. Two previous studies have shown that 6MWD was substantially lower among ARDS survivors than controls $1-2$ years after mechanical ventilation ${ }^{14} 45$ while the absence of systemic steroid treatment, the absence of illness acquired and rapid resolution of lung injury, and rapid resolution of lung injury during ICU stay were important factors associated with a longer 6MWD at 3, 6, and 12 months, respectively. ${ }^{14}$ In contrast, our analysis has shown that a longer hospital stay and female sex were independent factors associated with lower 6MWD at 3 months whereas age and female sex were negative predictors for 6MWD at 6 months. During hospitalisation for an average of 3 weeks, most of our patients were on bed rest because of respiratory failure. Given the relatively well preserved lung function in the majority of our SARS survivors, the poor performance in 6MWT in all age groups could be due to additional factors such as muscle wasting, steroid myopathy, and possibly cardiac diastolic dysfunction. ${ }^{46}$ In a study of the physical profile of SARS survivors $(\mathrm{n}=171$ and including the current cohort) at 3 months after illness onset, Lau et al ${ }^{47}$ noted that muscle strength and endurance were more impaired in proximal than in distal muscles. This was reflected by "average" handgrip measured by a hand-held dynamometer and "below average" to "poor" performance for curl-up and push-up testing compared with the normative Hong Kong data. Ong et al ${ }^{48}$ have recently reported that 18 of 44 SARS survivors in Singapore had reduced exercise capacity at 3 months after hospital discharge that could not be accounted for by impairment of pulmonary function. Their results suggest that the inability to exercise in recovered SARS patients is primarily due to extrapulmonary disease and is probably caused by myopathy or physical deconditioning. ${ }^{48}$

In addition, at 6 months there was significant impairment in HRQoL as measured by the Chinese version of the SF-36 questionnaire $^{27} 28$ in most domains. There were significant and positive correlations between lung function parameters (VC, FVC, FEV 1 , and TLCO) and SF-36 domains such as PF, $\mathrm{RP}, \mathrm{GH}$, and SF. The results are not surprising as, in addition to the physical impairment, the long period of isolation and extreme uncertainty during the SARS illness had created tremendous psychological and mood disturbances. Other contributing factors included intense media attention, bereavement, phobia, and rejection of SARS survivors by some members of the general public (particularly in the initial phase of the outbreak), and fear of transmission of SARS to others. ${ }^{40}$ Other studies on ALI or ARDS survivors unrelated to SARS have reported impaired HRQoL at 15 years after recovery, ${ }^{13-16}$ whereas pulmonary function abnormalities, especially TLCO, were correlated with SF-36 domains. ${ }^{15} 16$

Herridge et $a^{14}$ reported that $20 \%$ of their ARDS survivors had minor abnormalities on the chest radiograph at 1 year. Our study has shown that 33 subjects (30\%) still had abnormal radiographic scores at 6 months. The positive correlation between the extent of residual radiographic abnormalities and the cumulative steroid dosage used for SARS was not surprising as the former was an indication on the treatment protocol for more systemic steroid during the outbreak. ${ }^{5623}$ The negative correlation between residual radiographic abnormalities and lung volume parameters (FVC, TLC) and parameters of surface area for gas exchange (TLCO and KCO) reflected the physiological effects of parenchymal inflammation and fibrosis. Patients with more severe disease (as reflected by higher peak LDH) ${ }^{63} 39$ who had required ICU support during the acute illness tended to have more residual opacities on the chest radiograph at 6 months. In addition, they had more extensive pulmonary injury and fibrosis as reflected by significantly lower lung volume parameters (FVC and TLC) and transfer factor (TLCO) at 6 months than those treated on the general wards. There were, however, no significant differences in 6MWD and HRQoL between the two groups at 6 months. In addition, there were no differences in any functional parameters between mechanically ventilated and non-ventilated ICU patients. It is interesting that, in those patients surviving to the chronic phase of SARS related ARDS, HRCT scanning showed no visible differences between the patients who had been mechanically ventilated and those who had not. ${ }^{49}$

A significant proportion of SARS patients had evidence of respiratory muscle weakness, as reflected by decreased Pimax and Pemax values below $80 \mathrm{~cm} \mathrm{H}_{2} \mathrm{O}$ in 15 (13.9\%) and 24 $(22.2 \%)$, respectively, at 6 months. Weakness of the expiratory muscles (abdominal and intercostal muscles) could lead to air trapping (as reflected by increased RV above 120\% of predicted in some patients), whereas inspiratory muscle weakness may lead to atelectasis. There are many possible causes for respiratory muscle weakness among SARS survivors. Many patients complained of myalgia with elevation of creatinine kinase suggestive of viral induced myositis at initial presentation. ${ }^{6}$ At least $40 \%$ of patients suffered from acute respiratory failure requiring supplemental oxygen and bed rest during the second phase of the disease. $^{5-823}$ The long period of bed rest could lead to muscle wasting and deconditioning, while the use of systemic corticosteroids to suppress immune mediated lung injury ${ }^{5-8}$ could contribute to myopathy. In 13 patients given high dose steroids for acute lung transplant rejection over 5 days, about $45 \%$ developed acute generalised muscle weakness which 
took about 2 months to recover..$^{50}$ Similarly, myopathy has been observed in patients with status asthmaticus treated with high dose corticosteroid..$^{51}{ }^{52}$ Corticosteroids are thought to produce adverse effects on muscles through several mechanisms: altered electrical excitability of muscle fibres, loss of thick filaments, and/or inhibition of protein synthesis. $^{53-56}$

Interestingly, seven patients $(6.4 \%)$ without any past history of airway disease had a significant bronchodilator response to salbutamol ${ }^{30}$ with increments of $\mathrm{FEV}_{1}$ of at least $12 \%$ and over $200 \mathrm{ml}$ from baseline at 3 months, but the positive response was no longer present at 6 months. Although these patients had neither wheeze nor persistent cough at follow up, the bronchodilator response suggested that transient bronchial hyperresponsiveness might develop after SARS. Although we did not perform bronchial challenge in our patients, bronchial reactivity has been observed in some survivors of ARDS. ${ }^{42}$ Viral respiratory infections may cause increased airway responsiveness which can be observed in response to inhalation of histamine, methacholine, citric acid, or allergen. ${ }^{57-60}$

There are several limitations to this study. Firstly, we assessed inspiratory and expiratory muscle strength with mouth pressure, but low Pemax values do not always indicate expiratory muscle weakness and might result from technical difficulties such as mouth leakage. However, it is a well established simple test $\mathrm{t}^{32}{ }^{33}$ and none of our patients suffered from facial muscle or bulbar weakness. Cough gastric pressure provides a useful complementary test for the assessment of expiratory muscle strength but it involves insertion of a gastric balloon catheter and cough. ${ }^{61}$ At the time of planning this study there was still some concern among our lung function staff about potential infectivity via respiratory secretion of SARS survivors even though published data suggested this to be unlikely. ${ }^{5}$ It was therefore decided not to involve any invasive procedure. Lastly, although full lung function tests and 6 MWT were conducted in our patients, we did not perform cardiopulmonary exercise testing as most of our patients were complaining of generalised muscle weakness on follow up. In addition, cardiopulmonary exercise testing would be too labour intensive for the large cohort of SARS survivors. Nevertheless, reduced pulmonary gas exchange can be detected with cardiopulmonary exercise testing in many survivors of SARS at 3 months $^{48}$ and other causes of ARDS ${ }^{17}$ with normal TLCO.

In summary, this study has shown significant impairment of surface area for gas exchange in $15.5 \%$ of SARS survivors, while their functional ability and health status were significantly lower than the general population at 6 months after illness onset. The functional disability appears out of proportion to the degree of lung function impairment and may be due to additional factors such as muscle deconditioning and steroid myopathy. Long term follow up is needed to determine whether these deficits persist.

\section{ACKNOWLEDGEMENTS}

The authors would like to thank the following colleagues who have offered tremendous help in this ongoing study: PY Chan RN, MS Cheng RN, TY Cheong RN, MY Leung EN, Erica Lee (clerk) and Catherine Ho (research assistant). They would also like to acknowledge the Coordinating Committee in Physiotherapy, HK Hospital Authority, for collecting the updated normative data on 6 minute walk distances. They also thank Dr CC Szeto for his statistical advice on the data analysis.

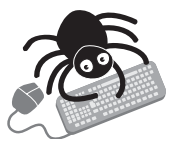

Further data are given in a supplementary file available on the Thorax website at http://www. thoraxjnl.com/supplemental.

\section{Authors' affiliations}

D S Hui, C S Cockram, J J Y Sung, Center for Emerging Infectious Diseases, Chinese University of Hong Kong, Prince of Wales Hospital, Shatin, NT, Hong Kong

D S Hui, F W Ko, M C Chan, D P Chan, M W Tong, C S Cockram, J J Y Sung, Department of Medicine and Therapeutics, Chinese University of Hong Kong, Prince of Wales Hospital, Shatin, NT, Hong Kong

G M Joynt, C D Gomersall, T S Li, Department of Anaesthesia and Intensive Care, Chinese University of Hong Kong, Prince of Wales Hospital, Shatin, NT, Hong Kong

K T Wong, G Antonio, A T Ahuja, Department of Diagnostic Radiology and Organ Imaging, Chinese University of Hong Kong, Prince of Wales Hospital, Shatin, NT, Hong Kong

T H Rainer, Accident and Emergency, Chinese University of Hong Kong, Prince of Wales Hospital, Shatin, NT, Hong Kong

Source of funding: Research Fund for the Control of Infectious Diseases (Health, Welfare and Food Bureau, HKSAR).

\section{REFERENCES}

1 Kuiken T, Fouchier RA, Schutten M, et al. Newly discovered coronavirus as the primary cause of severe acute respiratory syndrome. Lancet 2003;362:263-70

2 Drosten C, Gunther S, Preiser W, et al. Identification of a novel coronavirus in patients with severe acute respiratory syndrome. N Engl J Med 2003;348:1967-76

3 Ksiazek TG, Erdman D, Goldsmith CS, et al. A novel coronavirus associated with severe acute respiratory syndrome. N Engl J Med 2003;348:1953-66.

4 World Health Organization. Summary of probable SARS cases with onset of illness from 1 November 2002 to 31 July 2003. http://www.who.int/csr/ sars/country/table2003_09_23/en (accessed 10 September 2003).

5 Peiris JSM, Chu CM, Cheng VCC, et al. Clinical progression and viral load in a community outbreak of coronavirus-associated SARS pneumonia: a prospective study. Lancet 2003;361:1767-72.

6 Lee N, Hui DS, Wu A, et al. A major outbreak of severe acute respiratory syndrome in Hong Kong. N Engl J Med 2003;348:1986-94.

7 Chan JW, Ng CK, Chan YH, et al. Short term outcome and risk factors for adverse clinical outcomes in adults with severe acute respiratory syndrome (SARS). Thorax 2003;58:686-9.

8 Tsui PT, Kwok ML, Yuen H, et al. Severe acute respiratory syndrome: Clinical outcome and prognostic correlates. Emerg Infect Dis 2003:9:1064-9.

9 Nicholls JM, Poon LLM, Lee KC, et al. Lung pathology of fatal severe acute respiratory syndrome. Lancet 2003;361:1773-8.

10 Ding $Y$, Wang $\mathrm{H}$, Shen $\mathrm{H}$, et al. The clinical pathology of severe acute respiratory syndrome (SARS): a report from China. J Pathol 2003;200:282-9.

11 Franks TJ, Chong PY, Chui P, et al. Lung pathology of severe acute respiratory syndrome (SARS). A study of 8 autopsy cases from Singapore. Hum Pathol 2003;34:743-8.

12 Tse GM, To KF, Chan PK, et al. Pulmonary pathological features in coronavirus associated severe acute respiratory syndrome (SARS). J Clin Pathol 2004;57:260-5.

13 Weinert CR, Gross CR, Kangas JR, et al. Health-related quality of life after acute lung injury. Am J Respir Crit Care Med 1997;156:1120-8.

14 Herridge MS, Cheung AM, Tansey CM, et al. One-year outcomes in survivors of the acute respiratory distress syndrome. N Engl J Med 2003;348:683-93.

15 Schelling G, Stoll C, Vogelmeier C, et al. Pulmonary function and healthrelated quality of life in a sample of long-term survivors of the acute respiratory distress syndrome. Intensive Care Med 2000;26:1304-11.

16 Orme J Jr, Romney JS, Hopkins RO, et al. Pulmonary function and healthrelated quality of life in survivors of acute respiratory distress syndrome. Am J Respir Crit Care Med 2003; 167:690-4.

17 Neff TA, Stocker R, Frey HR, et al. Long-term assessment of lung function in survivors of severe ARDS. Chest 2003;123:845-53.

18 Booth CM, Matukas LM, Tomlinson GA, et al. Clinical features and short-term outcomes of 144 patients with SARS in the Greater Toronto area. JAMA 2003;289:2801-9.

19 Hsu LY, Lee CC, Green JA, et al. Severe acute respiratory syndrome in Singapore: clinical features of index patient and initial contacts. Emerg Infect Dis 2003:9:713-7.

20 Antonio GE, Wong KT, Hui DS, et al. Thin-section CT in patients with severe acute respiratory syndrome following hospital discharge: preliminary experience. Radiology 2003;228:810-5.

21 Wong RS, Hui DS. Index patient and SARS outbreak in Hong Kong. Emerg Infect Dis 2004; 10:339-41.

22 Centers for Disease Control and Prevention. Severe acute respiratory syndrome (SARS) updated interim US case definition. http://www.cdc.gov/ ncidod/sars/casedefinition.htm (accessed 20 April 2003)

23 Sung JJ, Wu A, Joynt GM, et al. Severe acute respiratory syndrome: report of treatment and outcome after a major outbreak. Thorax 2004;59:414-20.

24 Weisman IM, Zeballos RJ. Clinical exercise testing. Clin Chest Med $2001 ; 22: 679-701$

25 American Thoracic Society. Statement: Guidelines for the six-minute walk test. Am J Respir Crit Care Med 2002;166:111-7.

26 McHorney CA, Ware JE Jr, Lu JF, et al. The MOS 36-item Short-Form Health Survey (SF 36). III. Tests of data quality, scaling assumptions, and reliability across diverse patient groups. Med Care 1994;32:40-66. 
27 Lam CL, Gandek B, Ren XS, et al. Tests of scaling assumptions and construct validity of the Chinese (HK) version of the SF 36 health survey. J Clin Epidemiol 1998;51:1139-47.

28 Lam CL, Lauder IJ, Lam TP, et al. Population based norming of the Chinese (HK) version of the SF 36 health survey. Hong Kong Practitioner 1999;21:460-70

29 American Thoracic Society. Standardization of spirometry: 1994 update. Am J Respir Crit Care Med 1995;152:1107-36.

30 American Thoracic Society. Lung function testing: selection of reference values and interpretative strategies. Am Rev Respir Dis 1991;144:1202-18.

31 Da Costa JL. Pulmonary function studies in healthy Chinese adults in Singapore. Am Rev Respir Dis 1971;104:128-31.

32 Black LF, Hyatt RE. Maximal respiratory pressures: normal values and relationships to age and sex. Am Rev Respir Dis 1969;99:698-702.

33 ATS/ERS. Statement on respiratory muscle testing. Am J Respir Crit Med 2002; 166:518-624.

34 Koulouris N, Mulvey DA, Laroche CM, et al. Comparison of two different mouthpieces for the measurement of Pimax and Pemax in normal and weak subjects. Eur Respir J 1988; 1:863-7.

35 Chan CC, Cheong TH, Wang YT, et al. Transdiaphragmatic pressure in young adult Singaporean subjects: normal values and a comparison between different respiratory manoeuvres. Aust NZ J Med 1996;26:75-81.

36 Moxham J. Respiratory muscles. In: Hughes JM, Pride NB, eds. Lung function tests. Physiological principles and clinical applications. 1st ed. London: WB Saunders, 2000:57-72.

37 Wong KT, Antonio GE, Hui DS, et al. Severe acute respiratory syndrome: radiographic appearances and pattern of progression in 138 patients. Radiology 2003;228:401-6.

38 Enright PL, Sherrill DL. Reference equations for the six-minute walk in healthy adults. Am J Respir Crit Care Med 1998;158:1384-7.

39 Hui DS, Sung JJ. Severe acute respiratory syndrome (editorial). Chest 2003; 124:12-5.

40 Wong GW, Hui DS. Severe acute respiratory syndrome: epidemiology, diagnosis and treatment. Thorax 2003;58:558-60.

$41 \mathrm{Ng} \mathrm{CK}$, Chan JW, Kwan TL, et al. Six month radiological and physiological outcomes in severe acute respiratory syndrome (SARS) survivors. Thorax 2004:59:889-91.

42 Simpson DL, Goodman M, Spector SL, et al. Long-term follow-up and bronchial reactivity testing in survivors of the adult respiratory distress syndrome. Am Rev Respir Dis 1978;117:449-54.

43 Lakshminarayan S, Hudson LD. Pulmonary function following the adult respiratory distress syndrome. Chest 1978;74:489-90.

44 Peters JI, Bell RC, Prihoda TJ, et al. Clinical determinants of abnormalities in pulmonary functions in survivors of the adult respiratory distress syndrome. Am Rev Respir Dis 1989;139:1163-8.
45 Cooper AB, Ferguson ND, Hanly PJ, et al. Long-term follow-up of survivors of acute lung injury: lack of effect of a ventilation strategy to prevent barotraumas. Crit Care Med 1999;27:2616-21.

46 Li SS, Cheng CW, Fu CL, et al. Left ventricular performance in patients with severe acute respiratory syndrome. A 30 day echocardiographic follow-up study. Circulation 2003;108:r93-8.

47 Lau HM, Lee EW, Siu EH, et al. The impact of severe acute respiratory syndrome on the physical profile and quality of life in a cohort of survivors. Arch Phys Med Rehab 2005 (in press).

48 Ong KC, $\mathrm{Ng} \mathrm{AW}$, Lee LS, et al. Pulmonary function and exercise capacity in survivors of severe acute respiratory syndrome. Eur Respir $J$ 2004; $24: 436-42$

49 Joynt GM, Antonio GE, Lam P, et al. Late-stage adult respiratory distress syndrome caused by severe acute respiratory syndrome: abnormal findings at thin-section CT. Radiology 2004;230:339-46.

50 Nava S, Fracchia G, Callegari G, et al. Weakness of respiratory and skeletal muscles after a short course of steroids in patients with acute lung rejection. Eur Respir J 2002;20:497-9.

51 Kaplan PW, Rocha W, Sanders DB, et al. Acute steroid-induced tetraplegia following status asthmaticus. Paediatrics 1986;78:121-3.

52 Polsonetti BW, Joy SD, Laos LF. Steroid-induced myopathy in the ICU. Ann Pharmacother 2002;36:1741-4.

53 Mitch WE, Goldberg AL. Mechanisms of muscle wasting: the role of the ubiquitin-proteasome pathway. N Engl J Med 1996;335:1897-905.

54 Hund E. Myopathy in critically ill patients. Crit Care Med 1999;27:2544-7.

55 Larsson L, Li X, Edstrom L, et al. Acute quadriplegia and loss of muscle myosin in patients treated with nondepolarizing neuromuscular blocking agents and corticosteroids: mechanisms at the cellular and molecular levels. Crit Care Med 2000;28:34-45.

56 Dekhuijzen PH, Decramer M. steroid-induced myopathy and its significance to respiratory disease: a known disease rediscovered. Eur Respir $J$ 1992;5:997-1003.

57 Fraenkel DJ, Bardin PG, Sanderson G, et al. Lower airway inflammation during rhinovirus colds in normal and in asthmatic subjects. Am J Respir Crit Care Med 1995;151:879-86.

58 Sterk PJ. Virus-induced airway hyperresponsiveness in man. Eur Respir 1993;6:894-902

59 Laitinen LA, Elkin RB, Empey DW, et al. Bronchial hyperresponsiveness in normal subjects during attenuated influenza virus infection. Am Rev Respir Dis $1991 ; 143: 358-61$.

60 Trigg CJ, Nicholson KG, Wang JH, et al. Bronchial inflammation and the common cold: a comparison of atopic and non-atopic individuals. Clin Exp Allergy 1996;26:665-76.

61 Man WD, Kyroussis D, Fleming TA, et al. Cough gastric pressure and maximum expiratory mouth pressure in humans. Am J Respir Crit Care Med 2003;168:714-7

\section{LUNG ALERT}

Molecular techniques improve organism identification from pleural fluid in empyema

$\Delta$ Saglani S, Harris KA, Wallis C, Hartley JC. Empyema: the use of broad range $16 \mathrm{~S}$ rDNA PCR for pathogen detection. Arch Dis Child 2005:90:70-3

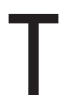
his study compares a broad range molecular technique with bacterial culture for the detection of organisms from pleural fluid in 32 children with empyema. The

concordance of organisms identified and influence of prior antibiotic treatment was also investigated. There was a median duration of 8 (1-42) days antibiotic therapy before pleural fluid aspiration.

The molecular assay is an established and validated broad range 16S rDNA PCR technique. This is based on bacterial ribosomal (r)DNA with sequencing of the PCR product to reveal the source organism. Significant organisms were detected in $19 \%$ of cases by culture, whilst $69 \%$ of cases were PCR positive. Of the six culture positive samples, five were PCR positive and the organism identified was identical using both techniques. The organism not detected by PCR was grown only after enrichment culture and was present at levels below the PCR detection limit. The presence of organisms detected by PCR but not culture was probably because of prior antibiotic treatment. The PCR negative cases had also all received antibiotic therapy, causing organism death and DNA degradation.

Molecular (non-culture) techniques improve organism identification from pleural fluid in children with empyema, even after commencement of antibiotics, but should be considered complementary to culture. This assay produces a result in 48 hours, allowing appropriate alterations in management soon within the inpatient stay.

T H Chapman Senior Clinical Fellow, Royal Free Hospital, London, UK; timothy.chapman@royalfree.nhs.uk 